\title{
Effect of Package Film on the Quality of Postharvest Chinese Toon Tender Shoots Storage
}

\author{
Yongqing $\mathrm{Zhu}^{1,2}$ and Jia Gao ${ }^{1,2}$ \\ ${ }^{1}$ Institute of Agro-Products Processing Science and Technology, Sichuan Academy of Agricultural Sciences, Chengdu 610066, China \\ ${ }^{2}$ Key Laboratory of Biology and Genetic Improvement of Horticultural Crops (Southwest Region), Ministry of Agriculture, \\ Chengdu 610066, China
}

Correspondence should be addressed to Yongqing Zhu; zhuyongqing68@sina.com

Received 21 June 2017; Accepted 23 October 2017; Published 13 November 2017

Academic Editor: Jordi Rovira

\begin{abstract}
Copyright (C) 2017 Yongqing Zhu and Jia Gao. This is an open access article distributed under the Creative Commons Attribution License, which permits unrestricted use, distribution, and reproduction in any medium, provided the original work is properly cited.

The young leaves and shoots of the Toona sinensis (A. Juss.) Roem. tree, called Chinese toon, are commonly eaten as a vegetable in China. This study was conducted to develop a modified atmosphere packaging (MAP) system for Chinese toon tender shoots and to evaluate the effect of film oxygen transmission rate (OTR) on package atmospheres and consequent product quality changes during storage. Fresh precooled Chinese toon tender shoots $(25 \pm 0.5 \mathrm{~g}$ each) were packaged in sealed $10 \mathrm{~cm} \times 15 \mathrm{~cm}$ polyethylene bags prepared with films of OTRs of $8.0,11.6,16.6,21.4$, or $29.5 \mathrm{pmol} \mathrm{s}^{-1} \mathrm{~m}^{-2} \mathrm{~Pa}^{-1}$ and stored at $4 \pm 0.5^{\circ} \mathrm{C}$ for 25 days. Evaluations included package atmospheres, tissue electrolyte leakage, color, and sensory attributes (overall visual quality, off-odor, texture, and marketability). Results indicated that the OTR of the package film significantly $(P<0.05)$ affected package headspace gas composition, $a^{*}$, hue angles, product quality, and shelf-life, under the tested package configurations and storage conditions. Packages with film OTR of $21.4 \mathrm{pmol} \mathrm{s}^{-1} \mathrm{~m}^{-2} \mathrm{~Pa}^{-1}$ attained stable $\mathrm{O}_{2}(8.4-10.0 \mathrm{kPa})$ and $\mathrm{CO}_{2}(2.2-3.0 \mathrm{kPa})$ levels by day 10 , which were maintained through the end of storage; products stored in these packages maintained freshness with high overall quality scores.
\end{abstract}

\section{Introduction}

Chinese toon is a tree in the Meliaceae or Mahogany. Its young leaves and shoots are favored as a popular spring tree vegetable in China. Toona sinensis is rich in bioactive compounds including flavonoids, alkaloids, terpenes, anthraquinones, and phenolics, which confer many health benefits, such as detoxification and anti-inflammation, anticancer, antidiabetes, antioxidative, and antithrombotic properties [1-4]. Tender Chinese toon is a seasonal vegetable which is extremely perishable, with high water content and a vigorous respiratory rate after harvest. Without intervention rapid dehydration resulting in wilted appearance, leaf abscission, lignification, browning, and decay occurs within 1-3 days of harvest. Thus, storage technologies that can maintain quality and prolong shelf-life of tender Chinese toon shoots are much needed. Refrigerated storage temperatures slow metabolism, reducing respiration rate and helping extend the shelf-life of Chinese toon shoots, but this is not sufficient to maintain high quality of the product. Modified atmosphere packaging (MAP) is an effective storage technology for maintaining quality and prolonging shelf-life of many horticultural commodities by matching the respiration rate of the packaged produce to the film's gas permeability and thus establishing an equilibrium $[5,6]$. The produce type and respiration rate, package film OTR, package weight and surface area, storage temperature, and relative humidity are important factors influencing the package headspace gas composition [7]. The headspace gas composition affects the produce quality; that is, too high $\mathrm{O}_{2}$ causes oxidation and too high $\mathrm{CO}_{2}$ causes tissue injury in some commodities. Therefore, the selection of a package film with suitable OTR for the specific fresh produce type along with optimal processing and storage conditions plays a key role in successful MAP storage technology.

Currently, there is little information on quality maintenance of Chinese toon tender shoots. The objective of this study was to develop MAP technology for fresh Chinese 
toon tender shoots by evaluating the influence of film OTR on package atmosphere, product quality, and shelflife.

\section{Materials and Methods}

2.1. Sample Processing and Packaging. Chinese toon tender shoots samples were harvested in Dazhu, which is called "China's first toon county," Sichuan province, China. The products were immediately packaged in plastic foam boxes with ice packs and transported to our laboratory within 4 hours, where they were stored at $4 \pm 0.5^{\circ} \mathrm{C}$ overnight and packaged within 2 days of harvest. The fresh Chinese toon tender shoot samples were selected for nonlignification, uniformity of size (10-15 cm length), bright vermilion color, and freedom from defects and mechanical damage. Samples $(25 \pm 0.5 \mathrm{~g})$ were packaged in sealed polyethylene bags $(10 \mathrm{~cm} \times 15 \mathrm{~cm}$, Pacific Southwest Container Inc., Modesto, CA, USA) with known OTRs of 8.0, 11.6, 16.6, 21.4, or $29.5 \mathrm{pmol} \mathrm{s}^{-1} \mathrm{~m}^{-2} \mathrm{~Pa}^{-1}$ and stored at $4 \pm 0.5^{\circ} \mathrm{C}$. The permeability of the films was tested by the manufacturer under conditions of $23^{\circ} \mathrm{C}$ and $101.3 \mathrm{kPa}$ using a MOCON apparatus according to ASTM F2714-08 and ASTM F2622-08 standards. The storage period was 25 days, or until the quality of the contents of a package dropped below commercial standards. Samples were evaluated after 3 and 5 days, and thereafter at internals of 5 days until day 25 , inclusively. There were four replicates (bags) for OTR for each evaluation day.

2.2. Analysis of Packaging Headspace Gas Composition. The package atmospheres were measured immediately upon removal of the samples from storage. The $\mathrm{O}_{2}$ and $\mathrm{CO}_{2}$ concentration of the samples were measured using a gas analyzer (CNOT-201 E, CNRO Science \& Technology CO., Ltd., Tianjin, CN) by inserting the needle of the measuring assembly through a septum adhered to the packaging film and pressing the measure button to automatically draw and analyze a headspace sample from each bag. Four bags per package condition were evaluated on each evaluation day.

2.3. Color Assessment. Each sample of Chinese toon tender shoots $(25 \pm 0.5 \mathrm{~g})$ that were placed on a white tray $(17 \times$ $13.5 \times 3 \mathrm{~cm})$ and color coordinates $\left(L^{*}, a^{*}, b^{*}\right)$ were measured directly on the leaf tissue using a colorimeter (CR400 Chroma Meter, Konica Minolta Optics. INC., JP) with a $50 \mathrm{~mm}$ diameter viewing aperture. The instrument was calibrated with a white tile $(Y=94.0, x=0.3130$, and $y=0.3191)$. Measurements were taken for $a^{*}$ and hue angles values at 20 random locations on each of the four replicates of each OTR condition.

2.4. Tissue Electrolyte Leakage. Tissue electrolyte leakage was measured following a modified procedure [8]. The contents of each package of Chinese toon tender shoots $(25 \pm 0.5 \mathrm{~g})$ were submerged in $300 \mathrm{~mL}$ of deionized water for $30 \mathrm{~min}$ at $20^{\circ} \mathrm{C}$, to assess fresh electrolyte leakage. The electrolyte content of the solution was determined by measuring the electrical conductivity (EC) with a conductivity meter (model DDSJ-308A, INESA Instrument, Inc., Shanghai, CN). Total electrolytes of the Chinese toon samples were then determined by measuring the EC after repeatedly three times freezing at $-20^{\circ} \mathrm{C}$ for $24 \mathrm{~h}$ and thawing at room temperature. Relative tissue electrolyte leakage (REC) was expressed as a ratio of the fresh over the total electrolytes measurements.

2.5. Sensory Attributes. A five-member trained panel comprising 4 females and 1 male ages 25-49 conducted the sensory evaluation of Chinese toon samples. Prior to the evaluation, training sessions were provided for the panelists on scoring the quality attributes. Reference sample packages exhibiting varying degrees of overall visual quality, aroma, and firmness were used to assist with the training. Aroma score was evaluated immediately after opening the packages and scored on a 1-9 scale, where 7-9 is strong fresh special aroma of toon, 5-7 is slight fresh special aroma of toon, 3-5 is no fresh special aroma of toon, with slight off-odor, and $1-3$ is only strong off-odor. The overall visual quality was assessed with a 1-9 hedonic scale where 9 is like extremely, fresh and light vermilion color, 5 is neither like nor dislike, limit of marketability, and 1 is dislike extremely, dark brown [6]. Texture was assessed by handling the shoots using fingers and scored on a 1-9 scale, where 7-9 is very crisp, 5-7 is crisp, 3-5 is becoming soft, and 1-3 is very soft. Marketability was rated on a 1-9 scale, where 7-9 is definitely would buy, 5-7 is would buy, 3-5 is might not buy, and 1-3 is definitely would not buy. The acceptable or marketable range for overall visual quality, marketability, aroma, and texture was considered to be a score of 5 or above.

2.6. Experimental Design and Statistical Analysis. Four replications (four bags) for each OTR package condition were evaluated on each evaluation day. Data was analyzed using SPSS 13.0 (SPSS Inc., Chicago, IL, USA) according to a twofactor linear model with storage time and packaging film as the factors. All data was reported as the mean of 4 replicates \pm standard error (SE).

\section{Results and Discussion}

3.1. Package Headspace Gas Composition. Headspace gas composition is an indication of a product's respiration rate which is directly proportional to metabolic rate [9]. Maintaining a stable atmosphere in the package during storage is achieved by matching respiration rate to package film OTR and is an effective means to delay quality deterioration. Figure 1 shows the changes in $\mathrm{O}_{2}$ and $\mathrm{CO}_{2}$ partial pressures in packages of Chinese toon tender shoots stored at $4^{\circ} \mathrm{C}$ for 25 days. Oxygen levels in the packages initially dropped rapidly and then declined gradually after day 5, until they reached equilibrium. Carbon dioxide concentration initially increased rapidly, followed by a slight decline, and then reached equilibrium on day 10 . Samples in packages with low OTR had greater depletion of $\mathrm{O}_{2}$ in the package and greater accumulation of $\mathrm{CO}_{2}$ (Figure 1). In packages with 


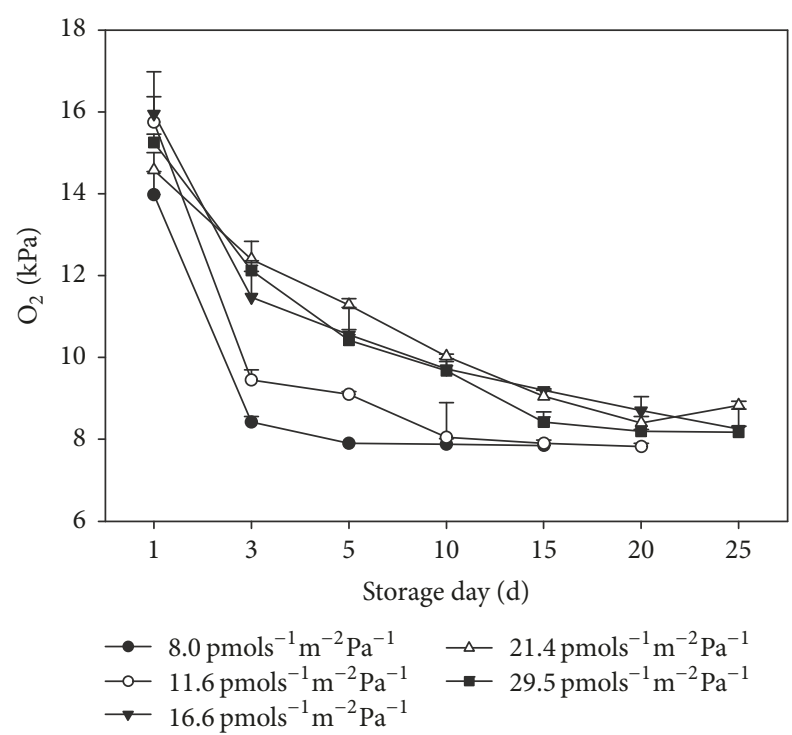

(a)

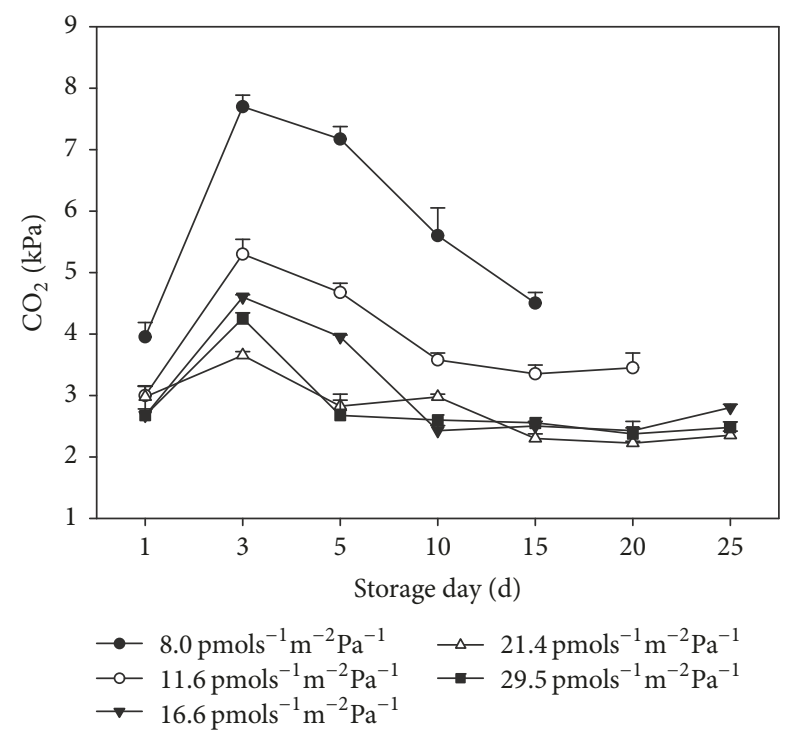

(b)

FIGURE 1: $\mathrm{O}_{2}$ and $\mathrm{CO}_{2}$ concentrations in package headspace as a function of storage time for Chinese toon tender shoots. Data points represent the mean $\pm \mathrm{SE}(n=4)$.

$8.0 \mathrm{pmol} \mathrm{s}^{-1} \mathrm{~m}^{-2} \mathrm{~Pa}^{-1}$ OTR, there was a more rapid decrease in $\mathrm{O}_{2}(7.9-8.4 \mathrm{kPa})$ and accumulation of $\mathrm{CO}_{2}(4.5-7.7 \mathrm{kPa})$ than in packages for other treatments from day 3 to day 15. Atmospheres in the packages with the two highest OTR (21.4 and $29.5 \mathrm{pmol} \mathrm{s}^{-1} \mathrm{~m}^{-2} \mathrm{~Pa}^{-1}$ ) always had higher levels of $\mathrm{O}_{2}$ and lower levels of $\mathrm{CO}_{2}$ and retained the $\mathrm{O}_{2}$ and $\mathrm{CO}_{2}$ level at $8.1-10.0 \mathrm{kPa}$ and $2.2-3.0 \mathrm{kPa}$, respectively, after day 10 (Figure 1). The packaging materials used in this experiment were the same as those previously reported for fresh-cut salad savory [6] and radish microgreens [10]. Comparing the results for these three different vegetables, there were similar trends for gas atmospheres for the different package

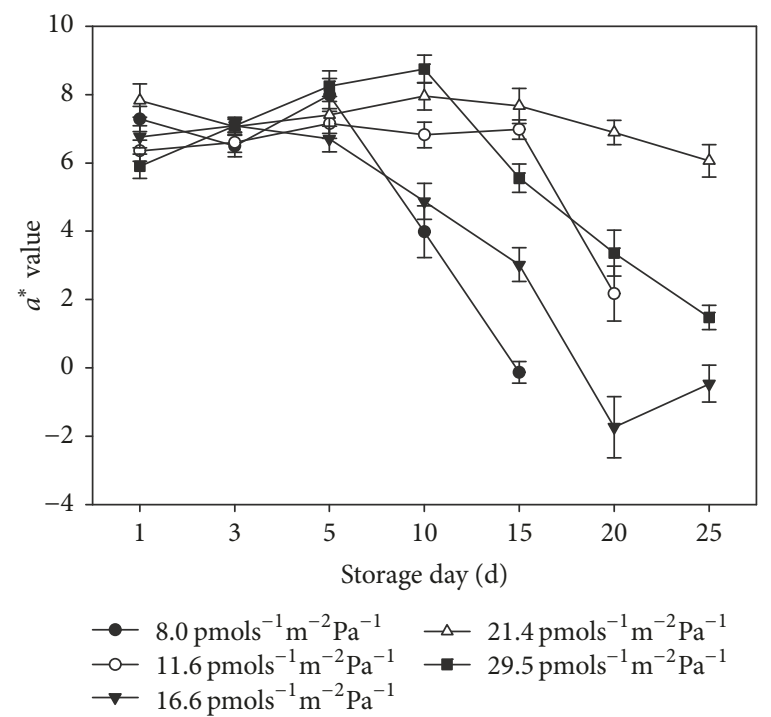

(a)

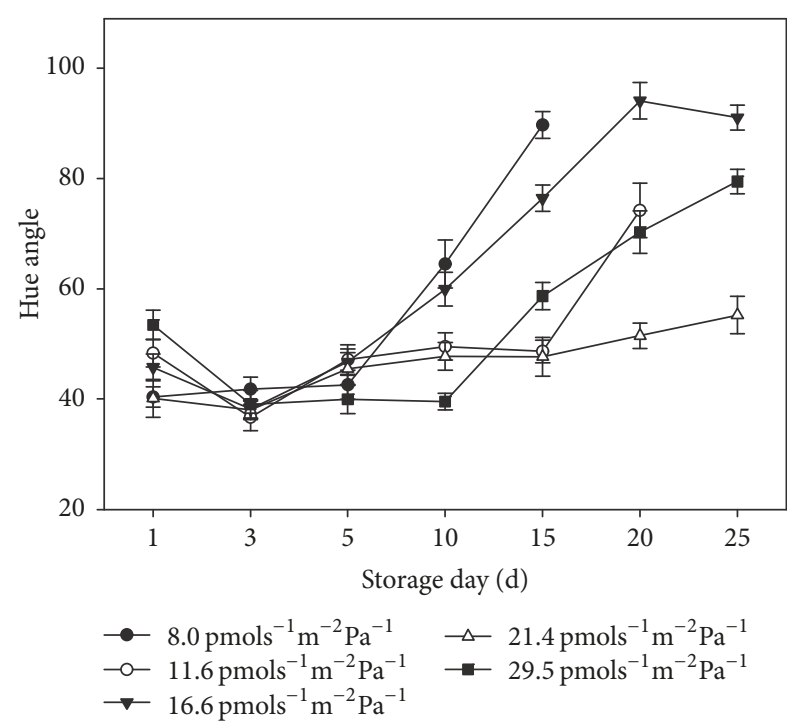

(b)

Figure 2: Color changes of Chinese toon tender shoots during storage at $4^{\circ} \mathrm{C}$ in packaging with various levels of OTR, expressed as changes in $a^{*}$ and hue angle values. Data points represent the mean $\pm \mathrm{SE}(n=80)$.

OTR films. However, these three vegetables have different respiration rates. Oxygen (and $\mathrm{CO}_{2}$ ) levels reached stability in packages of Chinese toon tender shoots at higher (and lower) values than for fresh-cut salad savory and at lower (and higher) values, respectively, than for radish microgreens.

3.2. Color Assessment. Fresh Chinese toon tender shoots have a bright vermilion color, but they gradually darken and turn brown or olive green as they senesce. Discoloration is a major concern with regard to quality deterioration of Chinese toon tender shoots during storage. Figure 2 shows 


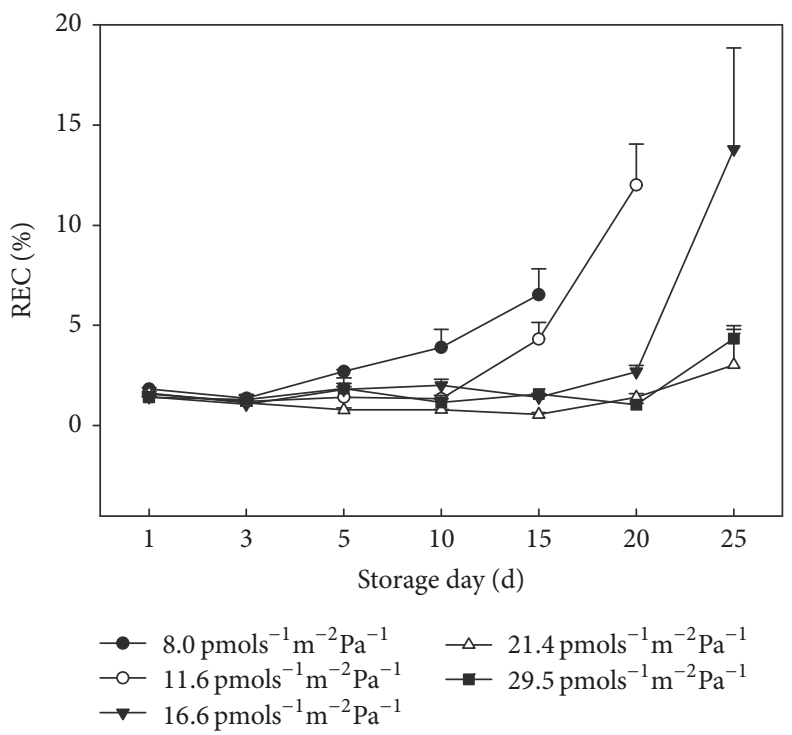

FIGURE 3: Effects of packaging with different OTR on tissue electrolyte leakage, expressed as relative electrical conductivity (REC), of Chinese toon tender shoots during storage at $4^{\circ} \mathrm{C}$. Data points represent the mean $\pm \operatorname{SE}(n=4)$.

the changes in $a^{*}$ and hue angle value of packaged Chinese toon tender shoots during storage at $4^{\circ} \mathrm{C}$. Changes in $a^{*}$ and hue angle value were significantly $(P<0.05)$ affected by the OTR of the package film. Samples packaged in 21.4 pmol s${ }^{-1} \mathrm{~m}^{-2} \mathrm{~Pa}^{-1}$ OTRs had the least change in $a^{*}$ value (7.9 to 6.1) and hue angle value (55.2 to 38.1) from the beginning to the end of 25-day storage period, respectively, indicating that they maintained their fresh leaf color. Packages with $8.0 \mathrm{pmol} \mathrm{s}^{-1} \mathrm{~m}^{-2} \mathrm{~Pa}^{-1}$ OTR exhibited a significantly $(P<0.01)$ reduced $a^{*}$ value on day 10 , with the leaf color becoming olive green. The changes in $a^{*}$ and hue angle values of samples packaged and stored in the remaining OTR packages were intermediate between those of the 21.4 and $8.0 \mathrm{pmol} \mathrm{s}^{-1} \mathrm{~m}^{-2} \mathrm{~Pa}^{-1}$ (Figure 2).

3.3. Tissue Electrolyte Leakage. Tissue electrolyte leakage is an indicator of cell membrane damage [11]. Values for the percent electrolyte leakage increased in all treatments with increased storage time (Figure 3). Electrolyte leakage in samples in packages which had 21.4 and $29.5 \mathrm{pmol} \mathrm{s}^{-1} \mathrm{~m}^{-2} \mathrm{~Pa}^{-1}$ OTR did not increase significantly by the end of the 25-day storage period $(P<0.01)$ compared to the starting values. In contrast, from day 5 onward the largest increases in electrolyte leakage $(P<0.05)$ were observed in packages with low OTR (Figure 3). Samples in the 8.0 and $11.6 \mathrm{pmol} \mathrm{s}^{-1} \mathrm{~m}^{-2} \mathrm{~Pa}^{-1}$ OTR packages had to be discarded after 15 days and 20 days, respectively, due to quality degradation.

3.4. Sensory Attributes. Overall visual quality and off-odor are important factors influencing the marketability of a food product [10]. Overall visual quality and off-odor of Chinese toon tender shoots were evaluated to determine whether the samples were acceptable at the end of storage. Offodor in produce packages is often an indicator of anaerobic respiration as well as decay under low $\mathrm{O}_{2}$ and elevated $\mathrm{CO}_{2}$ levels [6]. All of the sensory attributes evaluated were reduced by varying degree as storage time increased (Figure 4). At the end of storage, samples packaged in film with OTR of $21.4 \mathrm{pmol} \mathrm{s}^{-1} \mathrm{~m}^{-2} \mathrm{~Pa}^{-1}$ had the highest score for all the sensory attributes, all of which were above the acceptable level; they also had no off-odors. As observed in the color and REC data trends, samples stored in packages with $8.0 \mathrm{pmol} \mathrm{s}^{-1} \mathrm{~m}^{-2} \mathrm{~Pa}^{-1}$ OTR had the most dramatic changes, which were detected in off-odor and loss of marketability value after 10-day storage (Figure 4(d)). The intensity of negative sensory attributes increased over time, probably as a result of the depletion of $\mathrm{O}_{2}$ and accumulation of $\mathrm{CO}_{2}$.

Decrease in crispness or turgidity was minimal for all treatments and was not significantly different $(P<0.01)$ among the five levels of OTR in the tested packaging films. Unpackaged samples were also stored as control. The unpackaged control samples rapidly became dehydrated, softened, and wilted after 3 days of storage (data not shown) and were discarded without further storage or evaluation.

\section{Conclusions}

Film oxygen transmission rates significantly affected package atmospheres and the quality of Chinese toon tender shoots during storage. Packages $(10 \mathrm{~cm} \times 15 \mathrm{~cm})$ of Chinese toon tender shoots $(25 \pm 0.5 \mathrm{~g}$ per bag $)$ prepared with $21.4 \mathrm{pmol} \mathrm{s}^{-1} \mathrm{~m}^{-2} \mathrm{~Pa}^{-1}$ films and stored at $4 \pm 0.5^{\circ} \mathrm{C}$ achieved $\mathrm{O}_{2}$ and $\mathrm{CO}_{2}$ equilibrium levels (8.4-10.0 and $2.2-3.0 \mathrm{kPa}$, resp.). Products stored in these packages maintained good quality throughout 25 days of storage at $4 \pm 0.5^{\circ} \mathrm{C}$. Clearly, MAP using films with these OTR can prevent moisture loss, delay softening, and prolong the shelf-life of Chinese toon tender shoots after harvest. 


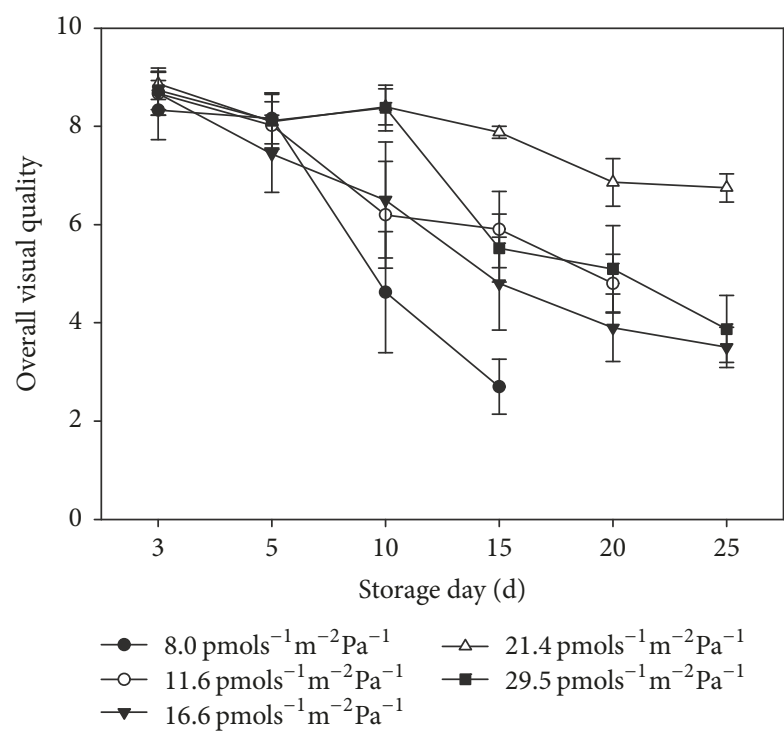

(a)

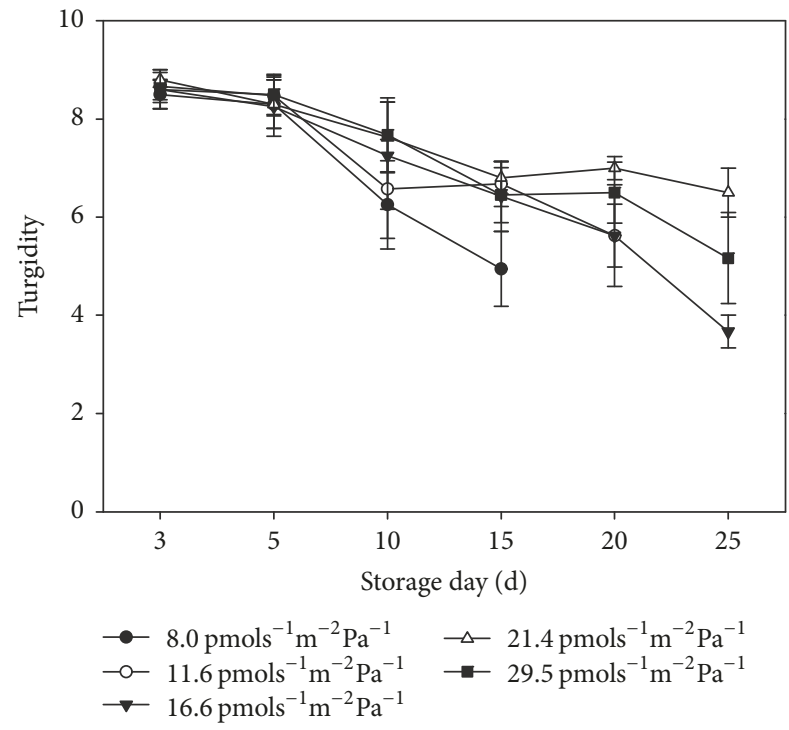

(c)

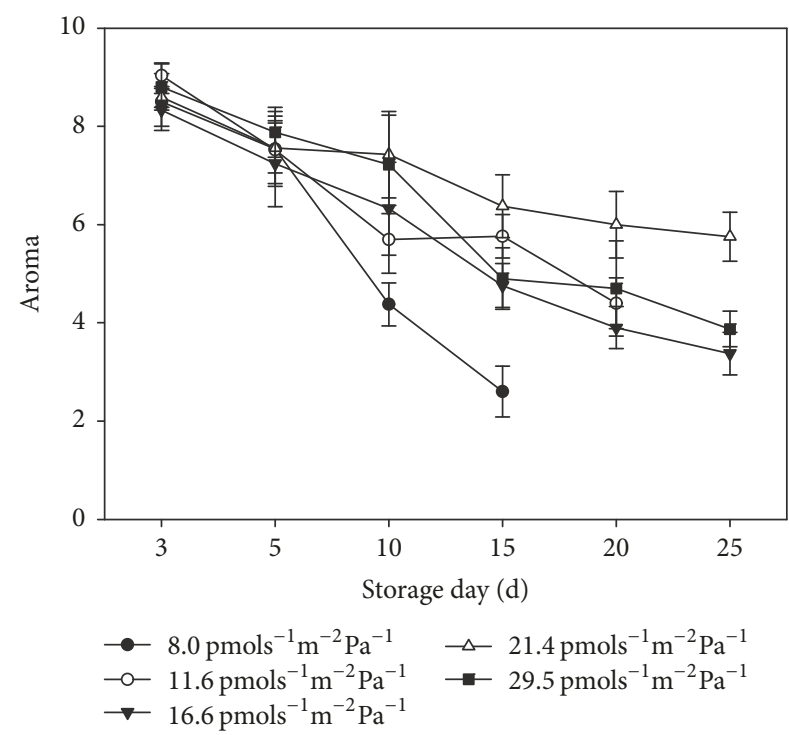

(b)

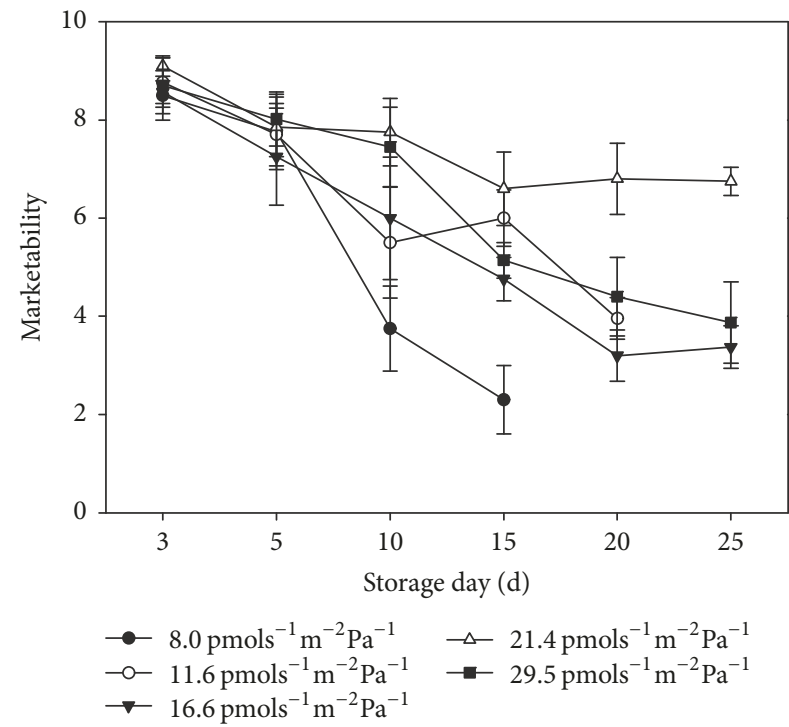

(d)

FIGURE 4: Sensory evaluation of Chinese toon tender shoots during storage at $4^{\circ} \mathrm{C}$ in packages with different OTR. Data points represent the mean $\pm \operatorname{SE}(n=5)$.

\section{Conflicts of Interest}

The authors declare that they have no conflicts of interest.

\section{Acknowledgments}

This work is supported by the International Science \& Technology Cooperation Program of China (Grant no. 2013DFA31450) and Science and Technology Support Program of Sichuan province (Grant no. 2014NZ0004).

\section{References}

[1] K.-W. Cheng, R.-Y. Yang, S. C. S. Tsou et al., "Analysis of antioxidant activity and antioxidant constituents of Chinese toon," Journal of Functional Foods, vol. 1, no. 3, pp. 253-259, 2009.

[2] K.-J. Wang, C.-R. Yang, and Y.-J. Zhang, "Phenolic antioxidants from Chinese toon (fresh young leaves and shoots of Toona sinensis)," Food Chemistry, vol. 101, no. 1, pp. 365-371, 2006.

[3] Y. Yan, Y. Min, H. Min, C. Chao, Q. Ying, and H. Zhi, "N-Butanol soluble fraction of the water extract of Chinese toon fruit ameliorated focal brain ischemic insult in rats via inhibition of oxidative stress and inflammation," Journal of Ethnopharmacology, vol. 151, no. 1, pp. 176-182, 2014.

[4] Y. Yang, J. Wang, Z.-E. Xing, Y.-Q. Dai, and M. Chen, "Identification of phenolics in Chinese toon and analysis of their content changes during storage," Food Chemistry, vol. 128, no. 4, pp. 831838, 2011.

[5] L. Jacxsens, F. Devlieghere, T. De Rudder, and J. Debevere, "Designing Equilibrium Modified Atmosphere Packages for 
Fresh-cut Vegetables Subjected to Changes in Temperature," LWT- Food Science and Technology, vol. 33, no. 3, pp. 178-187, 2000.

[6] J. G. Kim, Y. Luo, and K. C. Gross, "Effect of package film on the quality of fresh-cut salad savoy," Postharvest Biology and Technology, vol. 32, no. 1, pp. 99-107, 2004.

[7] Sandhya, "Modified atmosphere packaging of fresh produce: current status and future needs," LWT - Food Science and Technology, vol. 43, no. 3, pp. 381-392, 2010.

[8] H. Wang, H. Feng, and Y. Luo, "Microbial reduction and storage quality of fresh-cut cilantro washed with acidic electrolyzed water and aqueous ozone," Food Research International, vol. 37, no. 10, pp. 949-956, 2004.

[9] L. Kou, Y. Luo, E. Park, E. R. Turner, A. Barczak, and W. M. Jurick, "Temperature abuse timing affects the rate of quality deterioration of commercially packaged ready-to-eat baby spinach. Part I: Sensory analysis and selected quality attributes," Postharvest Biology and Technology, vol. 91, pp. 96-103, 2014.

[10] Z. Xiao, Y. Luo, G. E. Lester, L. Kou, T. Yang, and Q. Wang, "Postharvest quality and shelf life of radish microgreens as impacted by storage temperature, packaging film, and chlorine wash treatment," LWT-Food Science and Technology, vol. 55, no. 2, pp. 551-558, 2014.

[11] X. Fan and K. J. B. Sokorai, "Assessment of radiation sensitivity of fresh-cut vegetables using electrolyte leakage measurement," Postharvest Biology and Technology, vol. 36, no. 2, pp. 191-197, 2005. 

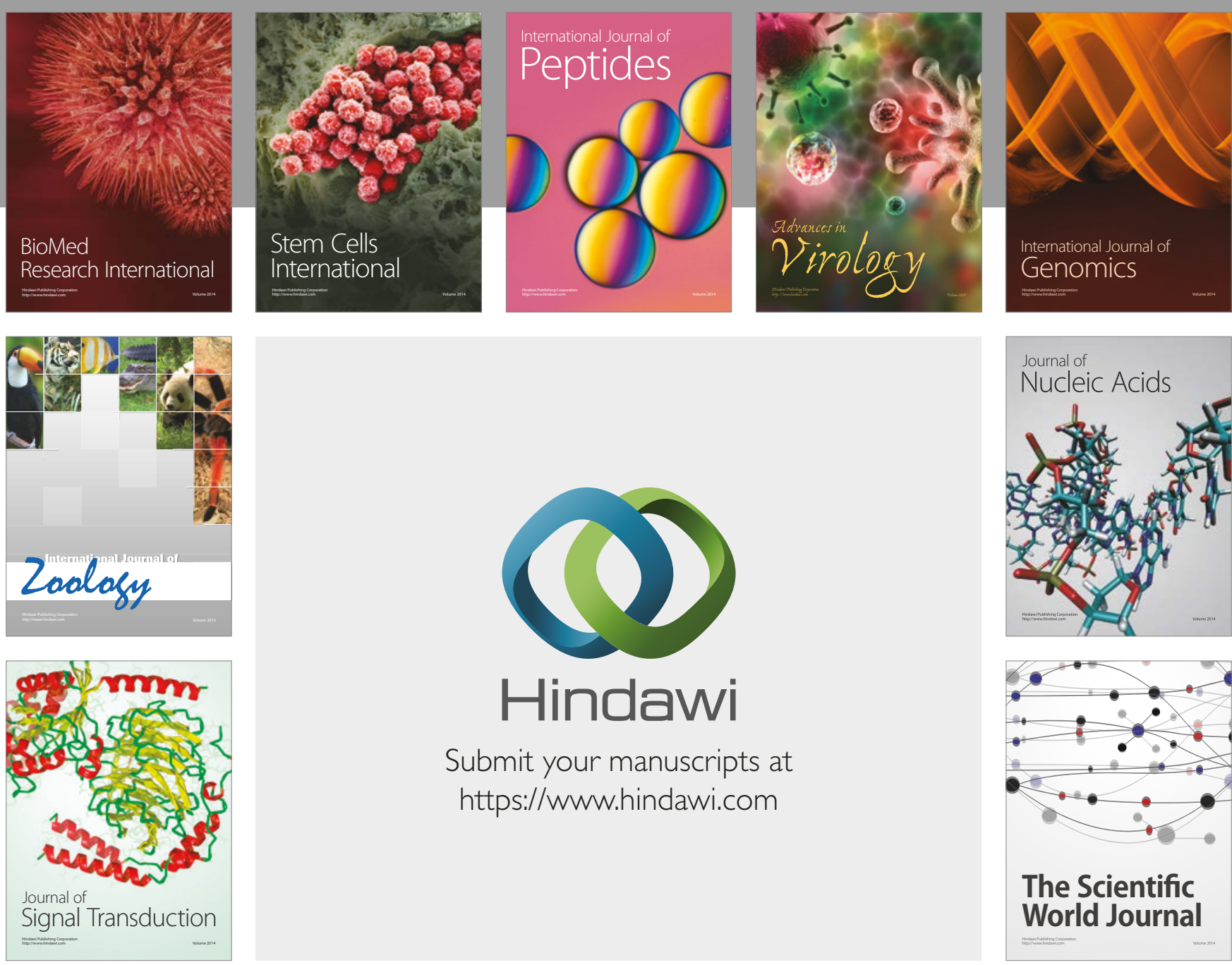

Submit your manuscripts at

https://www.hindawi.com
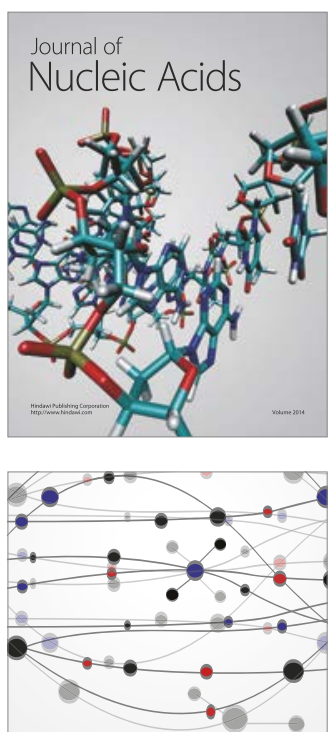

The Scientific World Journal

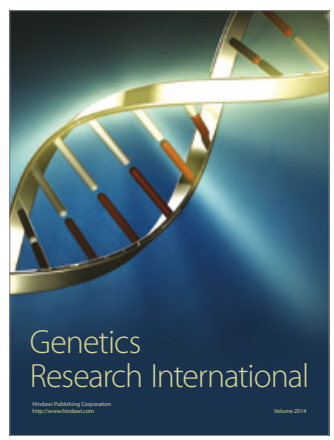

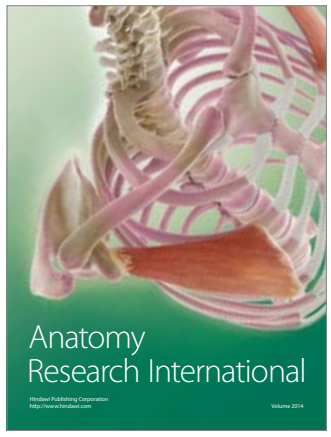

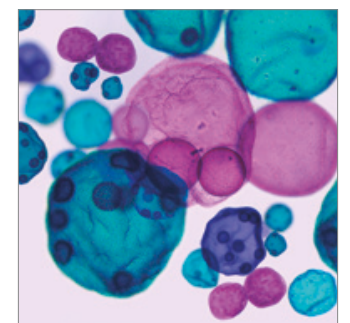

International Journal of Microbiology
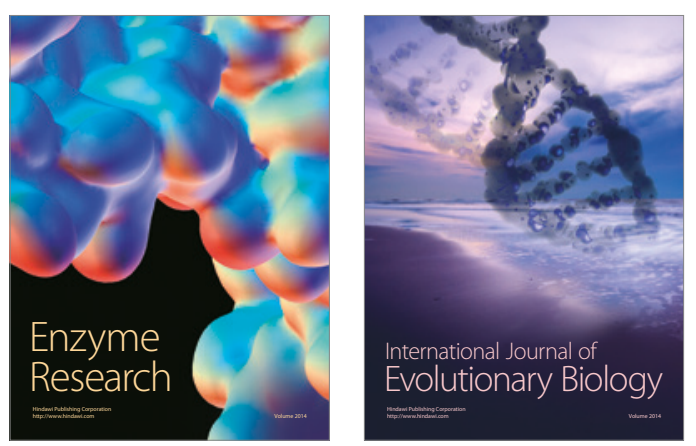
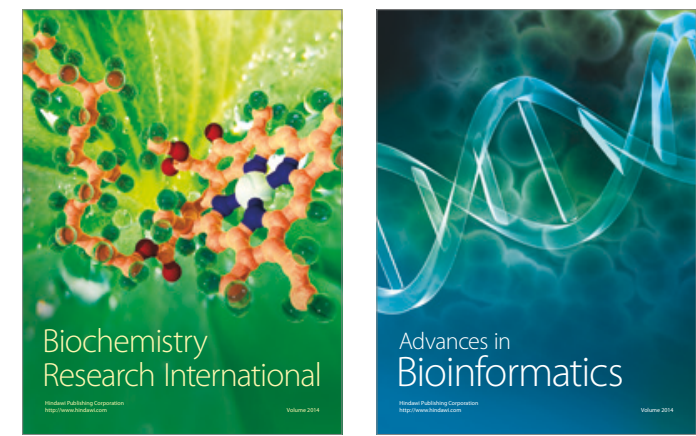

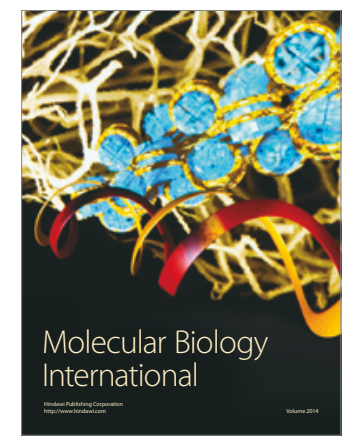

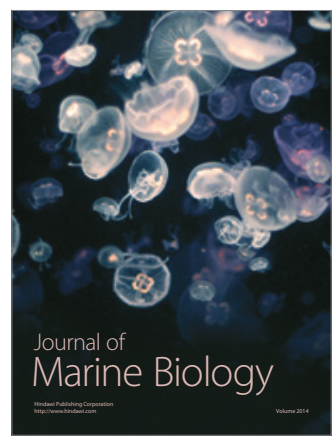

